\title{
Remember 2014?
}

It was the year that TMS held a record-breaking annual meeting in San Diego, California, and its inaugural Diversity Summit in Washington, D.C. It was the year TMS introduced two new journals and the Comic-tanium ${ }^{T M}$ exhibit. It was also the year the society took stock of where it has been and developed a new strategic plan to guide the next three years.
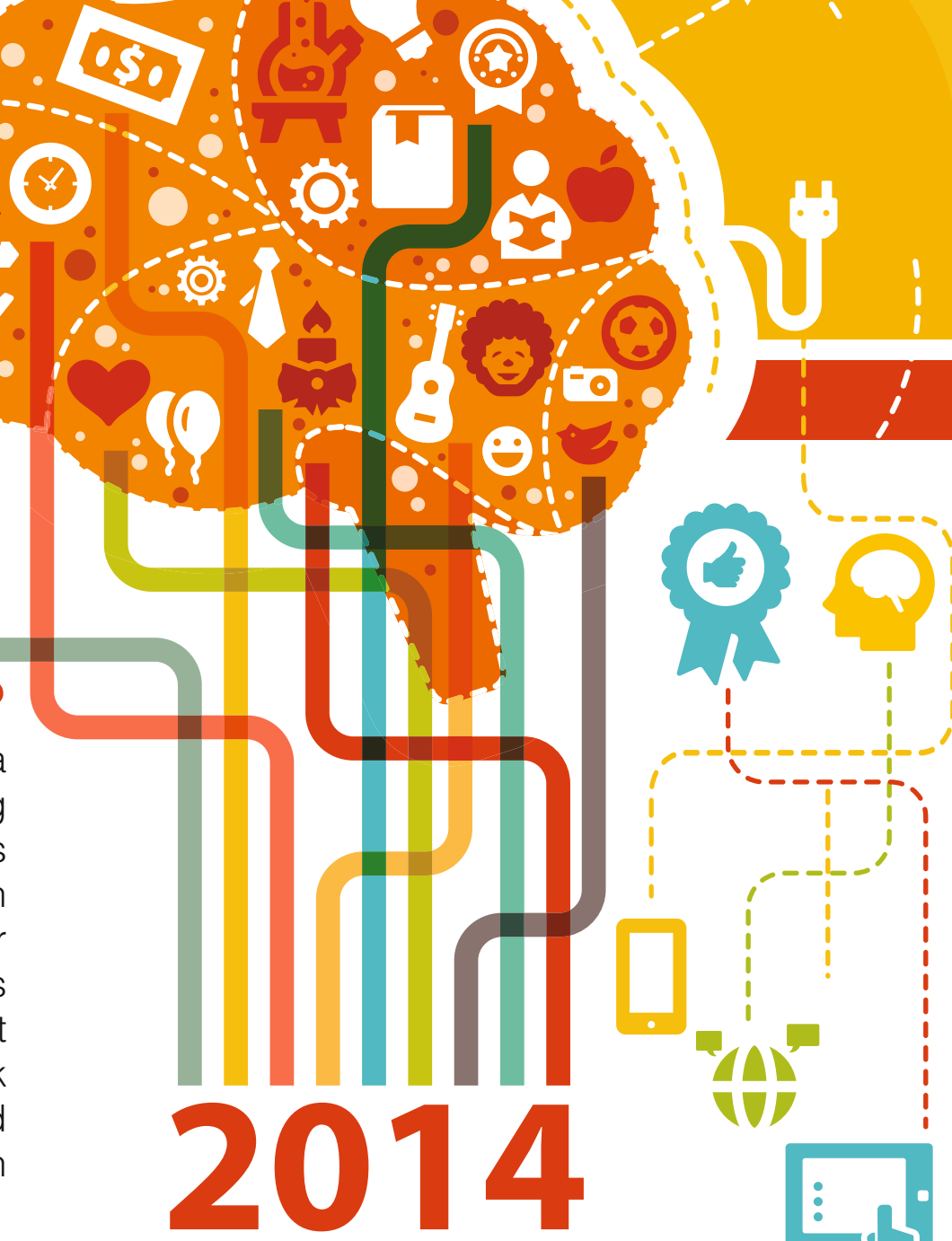


\section{STRATEGIC GOALS: A YEAR OF TRANSITION}

So why reminisce about 2014 now, as 2015 rounds to a close with its own sets of triumphs and accomplishments? The TMS Board of Directors recently approved the society's 2014 audited financial statements, allowing us to present a complete and accurate financial snapshot of the society's performance in 2014.

The financial statements can be found at the end of this article, and the numbers will tell the story of a society that achieved financial success that will enable it to sustain and develop member programs and services into the future.

What the financial statements don't show is how the society broke ground with new projects, improved existing programs and services to members, and, perhaps most significantly, positioned itself for future success by re-examining its strategic goals and priorities.

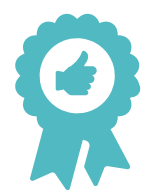

Every three years, TMS establishes a new strategic plan, consisting of five goals that guide the activities of the society. 2014 was a year of transition, where the society evaluated the success of the past three years and developed a new plan for the future. To provide a look at how our goals have evolved over this time period, the society's 2015 and 2018 strategic goals are listed below.

Some of the goals have stayed roughly the same - energy and environmental issues and materials and manufacturing innovation continue to be areas of strategic focus for the society - while others have evolved. Does this mean, for example, that TMS has shifted its focus from volunteers and young professionals? Certainly not. What it does mean is that over the past three years, the society has instituted a number of programs and processes in support of these areas, and these improvements have become an integral part of the society's culture and activities.

While a few 'new' goals have appeared on the list for 2018, it is important to note that they are not completely new ideas for the society.
Diversity and inclusion projects were a part of the 2015 Strategic Plan, but TMS's activities in this area have since expanded to include awards, meetings, and other initiatives, prompting the society to make Diversity and Inclusion Strategic Goal \#1 for 2018 .

Sustaining and growing the core activities that make up TMS is likewise an ongoing focus for the society, but the new strategic goals include more specific plans to expand international activities and accelerate industrial engagement to make sure the society meets the needs of the $40 \%$ of its members in industry.

The new strategic plan TMS developed to guide the society through 2018 is the result of a planning process conducted during the first half of 2014 that was a collaborative effort of TMS President Hani Henein, the TMS Executive Committee, TMS staff, and a facilitation team. In his letter to the membership in this October issue of JOM, 2015 TMS President Patrice E.A. Turchi addresses this new strategic plan more fully. (See "Don't Wonder What You'll Miss: The 2015 TMS President on What's Ahead for Members" for details.)

\section{Comparing Strategic Goals}

\section{TMS 2015 Strategic Goals} (Effective through the end of 2014)

1. Enhance our status as a volunteer-centric society

2. Be the destination society for young professionals: technically, professionally and socially

3. Sustain and grow our core as The Minerals, Metals \& Materials Society

4. Advance materials solutions for energy and environmental challenges

5. Be the recognized home for and advocate of materials and manufacturing innovation
TMS 2018 Strategic Goals

(Effective 2015 through year end 2017)

1. Advance diversity and inclusion in the minerals, metals, and materials profession

2. Accelerate industrial engagement in TMS

3. Globally expand the portfolio of international activities

4. Advance materials solutions for energy and environmental challenges

5. Be the natural home and advocate for materials and manufacturing innovation 


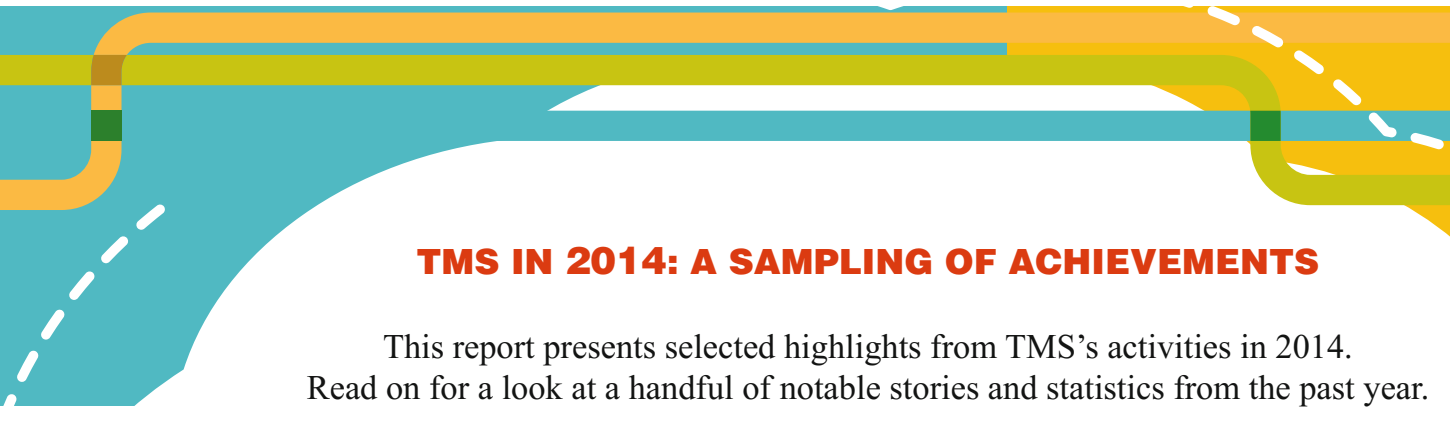

\section{TMS CAMPAIGNS FOR THE FOUNDATION}

In 2014, efforts to revitalize the TMS Foundation went into full swing. The TMS Foundation-the charitable arm of The Minerals, Metals \& Materials Societyprovides scholarships and travel grants to materials science and engineering students, leadership training and professional development programs for earlycareer professionals, and awards to recognize worthy individuals. The TMS Foundation has been performing all of these functions quietly and efficiently for more than 20 years, but in 2014, TMS stepped up its efforts to draw awareness to the work of the Foundation and to encourage members to support the programs the Foundation funds with financial contributions. A deliberate and focused appeal to members in 2014 resulted in a 129\% increase in donations to the Foundation in 2014 compared to 2013 .

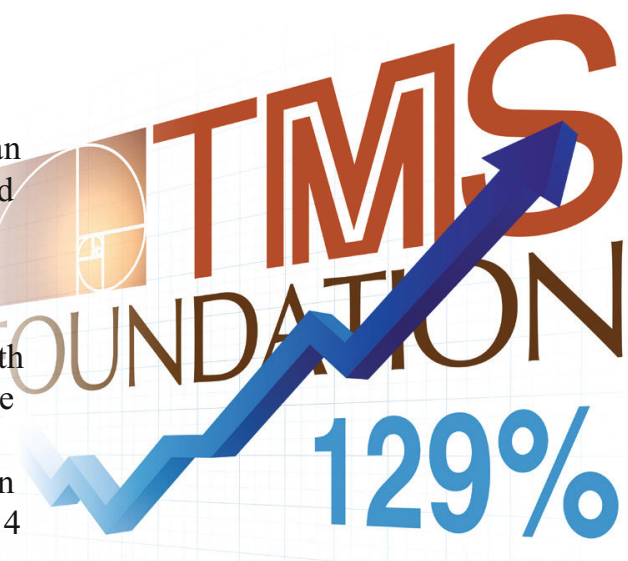

COMIC-TANIUM ${ }^{\text {TM }}$ DEBUTS AT TMS2014

When a science lesson requires you to wield Captain America's shield or don giant Incredible Hulk gloves, that's a lesson you won't soon forget. At the TMS 2014 Annual Meeting \& Exhibition (TMS2014), TMS unveiled Comic-tanium ${ }^{\mathrm{TM}}$ : The Super Materials of the Superheroes, a traveling educational exhibit that makes the connection between the real world of materials science and the fictional worlds of well-known comic book heroes. The exhibit encouraged TMS2014 meeting attendees, as well as groups of local students, to interact with and learn from the stories and information presented in the display. Developed by TMS, the TMS Foundation, and the ToonSeum, Comic-tanium traveled from the annual meeting to the USA Science and Engineering Festival in Washington, D.C. in April and ended 2014 with its public debut at the ToonSeum, a museum dedicated to the comic and cartoon arts in Pittsburgh, Pennsylvania, in October.

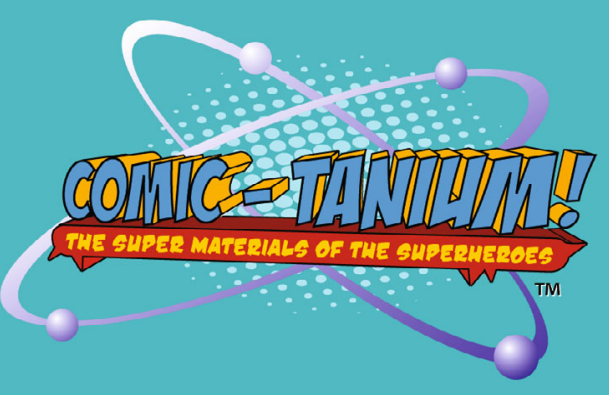

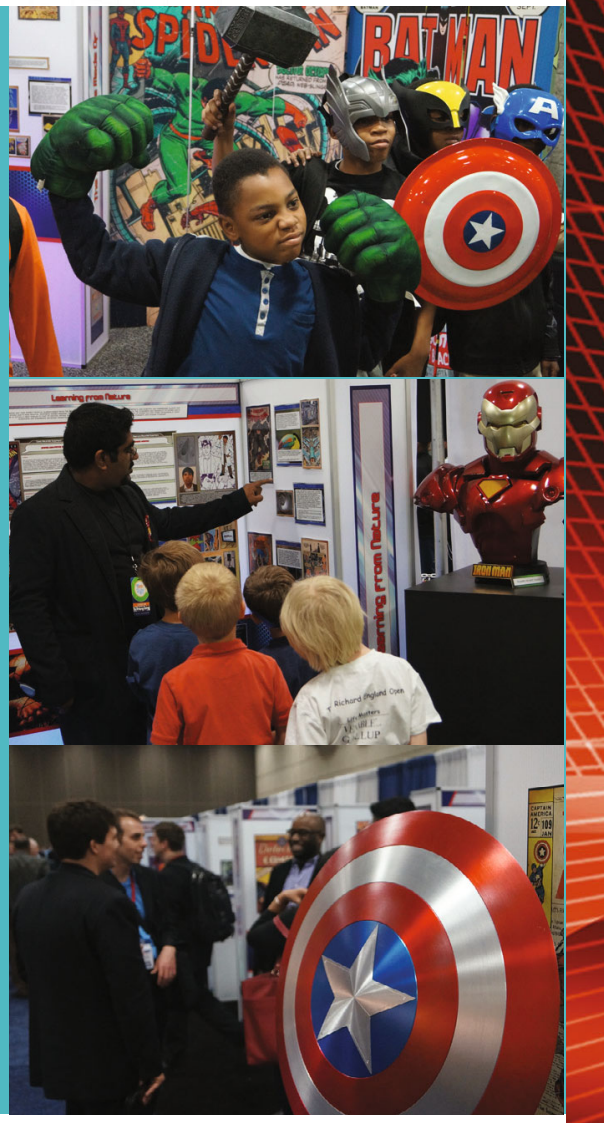




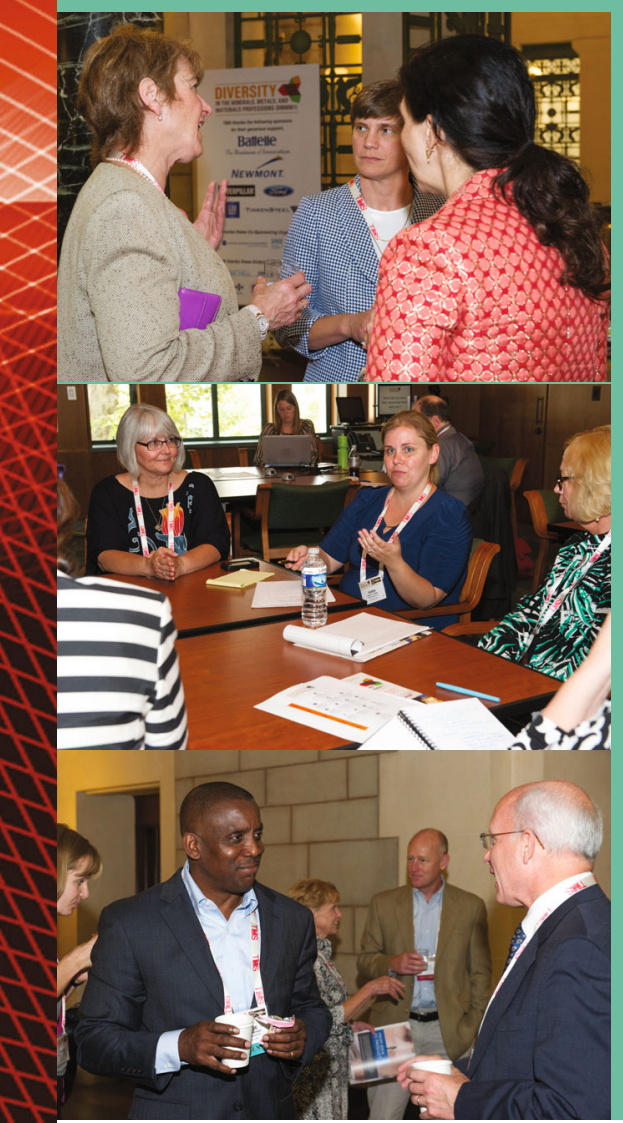

\section{DIVERSITY IN THE MINERALS, METALS, AND MATERIALS PROFESSIONS}

\section{In 2014, TMS established a} number of high-profile events and programs that will form the basis for meeting its 2018 strategic goal of advancing diversity and inclusion in the minerals, metals, and materials professions. The first TMS Summit on Diversity in the Minerals, Metals, and Materials Professions (DMMM1) was held at the U.S. National Academy of Sciences building in Washington, D.C. in July. DMMM1 featured keynotes from leaders in the field, professional development training, and facilitated discussions to develop practical solutions for diversity challenges. The event generated honest conversation among minerals, metals, and materials scientists and engineers working in all sectors and at all levels of experience.

The outcomes of these revealing discussions are recorded in the DMMM1 final report and toolkit, a pair of resources that are available for free download to scientists and engineers, human resources professionals, managers, and anyone interested in taking a closer look at the impact of diversity and inclusion issues in the workplace. Visit www .tms.org/DiversityReport to access the report.

TMS also awarded the first Ellen Swallow Richards Diversity Award in 2014 to Viola L. Acoff of the University of Alabama. Going forward, the society will continue to bestow the Richards award to those who help others to overcome diversity and will present a second award, the Frank Crossley Diversity Award, to those who have overcome diversity

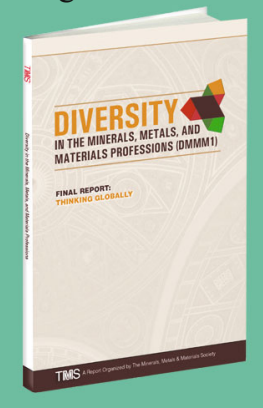
themselves.

\section{TMS LEADS NEW ROADMAPPING STUDY}

In April 2014, TMS began work on Modeling Across Scales: A Roadmapping Study for Connecting Materials Models and Simulations Across Length and Time Scales, the latest in a series of successful roadmapping study projects conducted by TMS. A core study team of internationally recognized experts from industry, academia, and government was assembled to work on this project with input from other leaders in multiscale materials modeling. The project was supported by a grant from the U.S. National Institute of Standards and Technology, Materials Measurement
Laboratory. The study project focused on developing recommendations for critical steps and pathways needed to link computational materials models and pass materials-related data and information across length and time scales for enhanced, quantitative multiscale modeling. Limitations in bridging these scales was identified as a significant barrier to innovation in the 2013 TMS study Implementing ICME in the Aerospace, Automotive, and Maritime Industries.

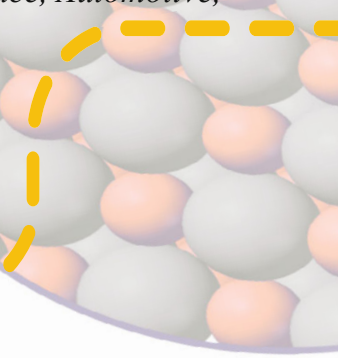

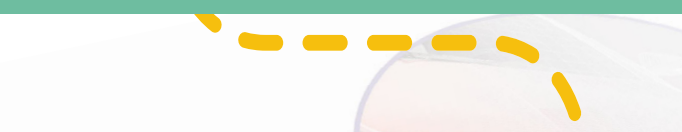




\section{TMS EXPANDS PROFESSIONAL DEVELOPMENT OPTIONS FOR MEMBERS}

As TMS works to expand its traditional professional development offerings-including more stand-alone workshops and courses - the society also kicked off a new series of webinars that provide professional development opportunities without the need for travel. The first webinar, "The Impact of Contextualized Computing for Materials Students," was offered as a live presentation at no charge to participants and can now be downloaded and viewed through TMS's Professional Development web pages. This exploration of webinar technologies to deliver professional development content to TMS members is the work of the TMS Ad Hoc Professional Development Committee, established in October 2014.

\section{TMS 2014 ANNUAL MEETING \& EXHIBITION IN BRIEF}

The TMS Annual Meeting \& Exhibition is the largest and most comprehensive event the society holds all year and the primary gathering place where TMS members meet and exchange ideas.

\section{WHO:}

4,315 ATTENDEES

(That's the highest attendance of the millennium.)

\section{3,406 TECHNICAL}

WHAT:

(another record number) and 262 meetings and networking events

\section{SAN DIEGO}

California
FEBRUARY $16-20,2014$
WHEN:

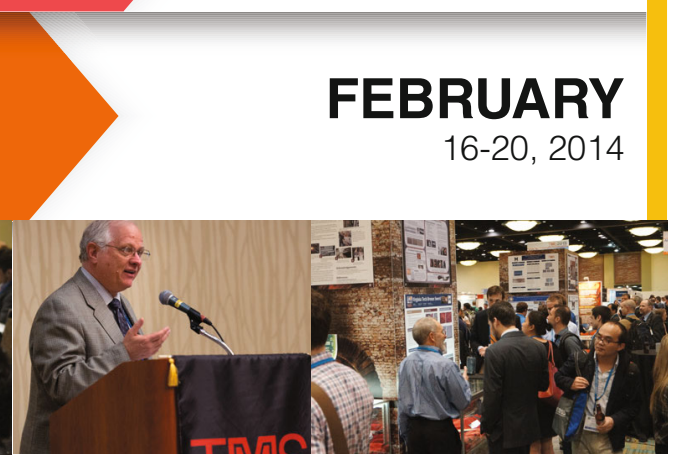

\section{TMS MEMBERSHIP BY THE NUMBERS}

TMS is a member-driven organization. It exists for the benefit of our members and because of the time, talents, and ideas they volunteer to TMS programs and activities. Growth in membership is always an indicator that the society is growing and thriving. Consider the following numbers:

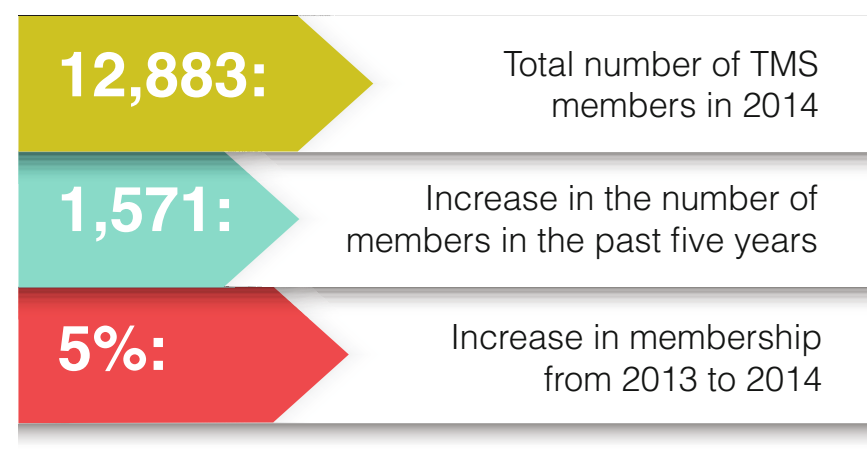

Employers of Professional Members

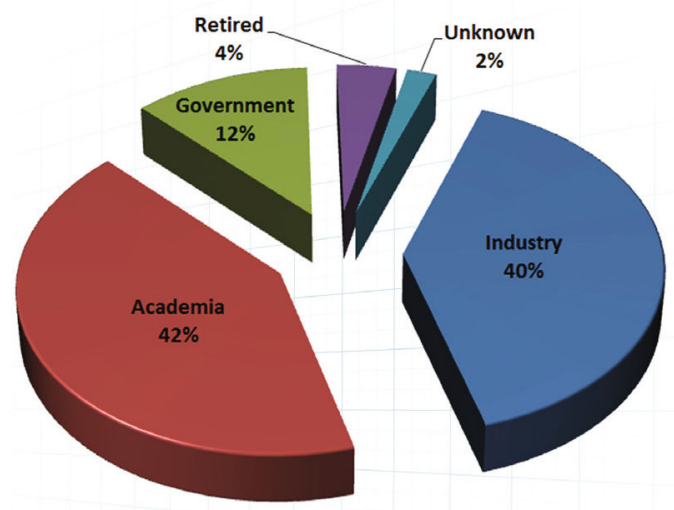

Professional Members by Region

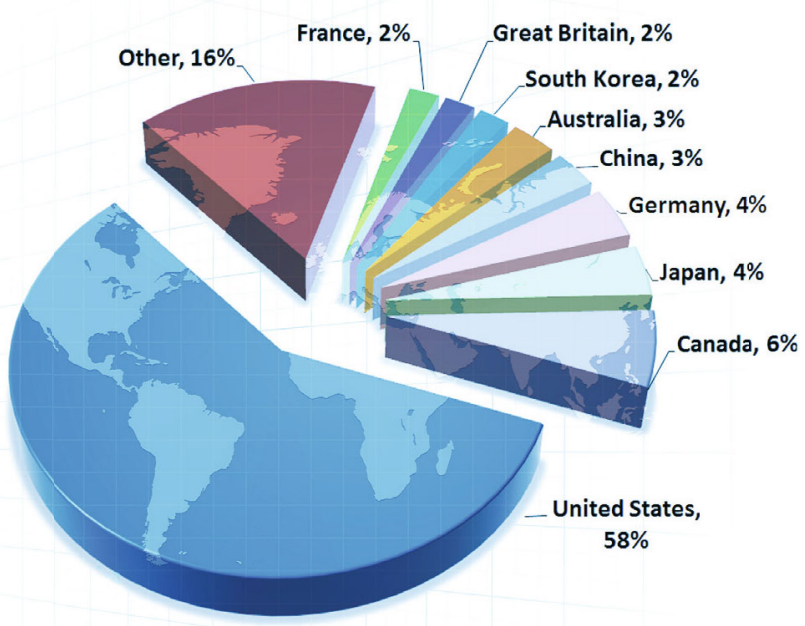




\section{FINANCIAL INFORMATION}

\section{Operating Revenues by Program Area}

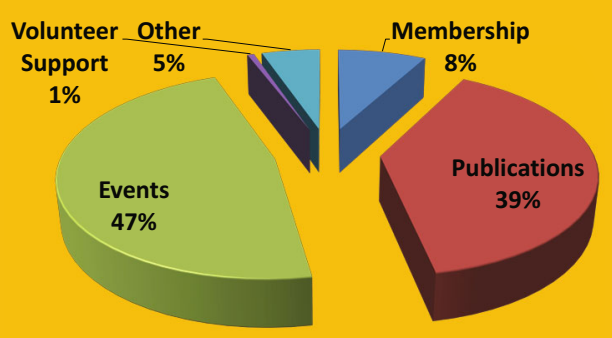

2014 Operating Expenses by Program Area

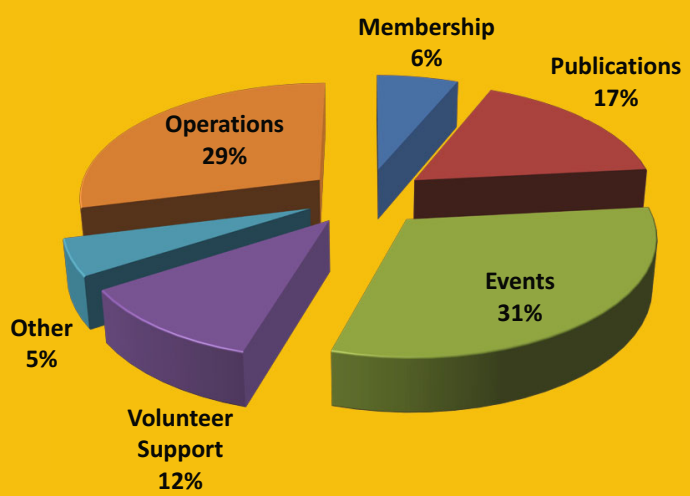

Summary of Operations Revenues and Expenses Years ending December 31, 2014 and 2013

\begin{tabular}{|l|l|l|}
\cline { 2 - 3 } \multicolumn{1}{l|}{ REVENUES } & \multicolumn{1}{c|}{$\mathbf{2 0 1 4}$} & \multicolumn{1}{c|}{$\mathbf{2 0 1 3}$} \\
\hline Membership & $\$ 572,852$ & $\$ 530,580$ \\
\hline $\begin{array}{l}\text { Editorial, Content \& } \\
\text { Communications }\end{array}$ & $\$ 2,840,784$ & $\$ 2,384,078$ \\
\hline Events, Programs \& Sales & $\$ 3,413,881$ & $\$ 3,619,786$ \\
\hline Contracts \& Grants & $\$ 205,750$ & $\$ 225,000$ \\
\hline Volunteer Support & $\$ 42,630$ & $\$ 45,517$ \\
\hline Executive/Operations & $\$ 172,770$ & $\$ 156,476$ \\
\hline TOTAL REVENUES & $\mathbf{\$ 7 , 2 4 8 , 6 6 7}$ & $\$ 6,961,437$ \\
\hline EXPENSES & & \multicolumn{1}{|l}{} \\
\hline
\end{tabular}

\begin{tabular}{|l|l|l|}
\hline Membership & $\$ 422,553$ & $\$ 352,551$ \\
\hline $\begin{array}{l}\text { Editorial, Content \& } \\
\text { Communications }\end{array}$ & $\$ 1,145,999$ & $\$ 998,217$ \\
\hline Events, Programs \& Sales & $\$ 2,099,769$ & $\$ 2,356,757$ \\
\hline Contracts \& Grants & $\$ 84,617$ & $\$ 113,936$ \\
\hline Volunteer Support & $\$ 759,741$ & $\$ 795,147$ \\
\hline Executive/Operations & $\$ 2,206,527$ & $\$ 1,879,283$ \\
\hline TOTAL EXPENSES & $\$ 6,719,206$ & $\$ 6,495,891$ \\
\hline
\end{tabular}

\begin{tabular}{|l|l|l|}
\hline $\begin{array}{l}\text { EXCESS OPERATIONS } \\
\text { REVENUE }\end{array}$ & $\$ 529,461$ & $\$ 465,546$ \\
\hline
\end{tabular}

\section{NEW TMS JOURNALS}

In 2014, TMS introduced two new journals:

- Metallurgical and Materials Transactions E, which joins the wellrespected Metallurgical and Materials Transactions $A$ and $B$ journals, and focuses on materials for energy systems, began publication in 2014.

- Journal of Sustainable Metallurgy issued its first call for papers in 2014. Its editorial focus is presenting metallurgical processes and related research aimed at improving the sustainability of metalproducing industries, with a particular emphasis on materials recovery, reuse, and recycling.

Both journals are currently accepting manuscript submissions.

Visit www.tms.org/Publications for more information.

\section{ESTABLISHED TMS JOURNALS}

All four of TMS's long-established journals marked increases in their Impact Factors for 2014. The Impact Factor represents the average number of citations to articles that were published during the preceding two years.

\section{MEMBERS OF THE TMS 2014 BOARD OF DIRECTORS}

TMS would like to thank the volunteers who contributed significant time and resources to helping the society achieve its goals in 2014 as members of the TMS Board of Directors. Current and retiring TMS Board Members include:

Front row, left to right: Patrice Turchi, Edward D. Herderick, Mark E. Schlesinger, Joy H. Forsmark, Amy Clarke, Roger Narayan.

Second row, left to right: James J. Robinson, David F. Bahr, Neville Moody, James C. Foley, Hani Henien, Stanley M. Howard, Rajiv S. Mishra, Elizabeth A. Holm.

Back row, left to right: Jeffrey Fergus, David H. DeYoung, Eric N. Brown, Robert W. Hyers.

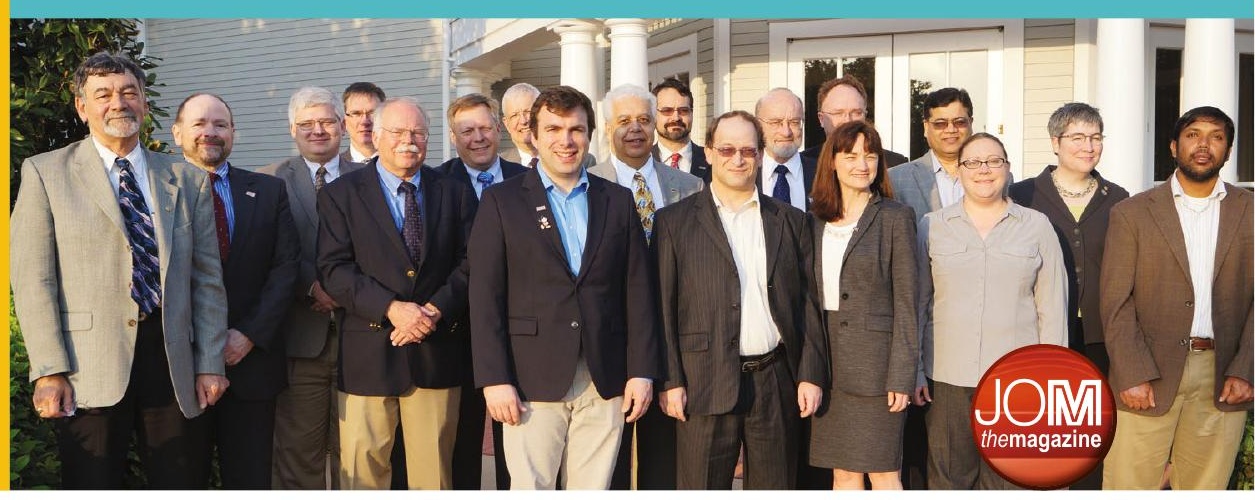

